\title{
Research on fault diagnosis for MMC-HVDC Systems
}

\author{
Zhiqing Yao ${ }^{* *}$, Qun Zhang ${ }^{2}$, Peng Chen $^{2}$ and Qian Zhao ${ }^{2}$
}

\begin{abstract}
Introduction: With the development of flexible HVDC technology, the fault diagnosis of MMC-HVDC becomes a new research direction.

Based on the fault diagnosis theory, this paper proposes a robust fault diagnosis method to study the fault diagnosis problem of MMC-HVDC systems.

Methods: By optimizing the gain matrix in the fault observer, fault detection with good sensitivity and robustness to disturbance is achieved. In the MMC-HVDC system, because of the inherently uncertain system and the presence of various random disturbances, the study of robust fault diagnosis method is particularly important.

Results: Simulation studies during various AC faults have been carried out based on a 61-level MMC-HVDC mathematical model. The results validate the feasibility and effectiveness of the proposed fault diagnosis method.

Conclusions: So this fault diagnosis method can be further applied to the actual project, to quickly achieve system fault diagnosis and accurately complete fault identification.
\end{abstract}

Keywords: Fault diagnosis, MMC-HVDC, Robust, State observer, Residual state equation

\section{Introduction}

In recent years, due to the increased size and complexity of control systems, fault diagnosis becomes particularly important, especially in power systems [1]. For instance, if line faults are not quickly detected and isolated, they can cause system failure or even lead to disastrous consequences [2]. Currently, there are many fault diagnosis methods, such as the diagnostic filter method, parameter identification method, expert system, artificial neural network etc. [3-5]. Although these methods can effectively detect failures in the system, they cannot precisely estimate these fault signals.

This paper proposes a fault diagnosis method based on full dimension state observer for flexible HVDC system. State estimation is carried out using the mathematical model of a three-phase 61-level modular multilevel converter (MMC) based HVDC (MMC-HVDC) system and the full dimension state observer. Residual state equation is established and is combined with the system output and system phasor. By optimizing the gain matrix in fault observer, the robustness of the fault detection is investigated. In the MMC-HVDC system, because the system is inherently uncertain and there are various random disturbances, the study of robust fault diagnosis method is particularly important.

\section{Methods}

\section{Model of MMC-HVDC}

A three-phase MMC topology is shown in Fig. 1 [6-9]. According to $\mathrm{KCL}$, the three-phase current can be expressed as

$$
\left\{\begin{aligned}
i_{a} & =i_{p a}+i_{n a} \\
i_{b} & =i_{p b}+i_{n b} \\
i_{c} & =i_{p c}+i_{n c}
\end{aligned}\right.
$$

For three single-phase units, applying KVL to the upper and lower arms yields:

$$
\left\{\begin{array}{l}
u_{a}-\left(\frac{U_{d c}}{2}-u_{p a}\right)=2 L \frac{d i_{p a}}{d t}+2 R i_{p a} \\
u_{b}-\left(\frac{U_{d c}}{2}-u_{p b}\right)=2 L \frac{d i_{p b}}{d t}+2 R i_{p b} \\
u_{c}-\left(\frac{U_{d c}}{2}-u_{p c}\right)=2 L \frac{d i_{p c}}{d t}+2 R i_{p c}
\end{array}\right.
$$

* Correspondence: zhiqingy@dlwg.net

${ }^{1}$ Xuchang KETOP Electrical Research Institute, Xuchang, China

Full list of author information is available at the end of the article 


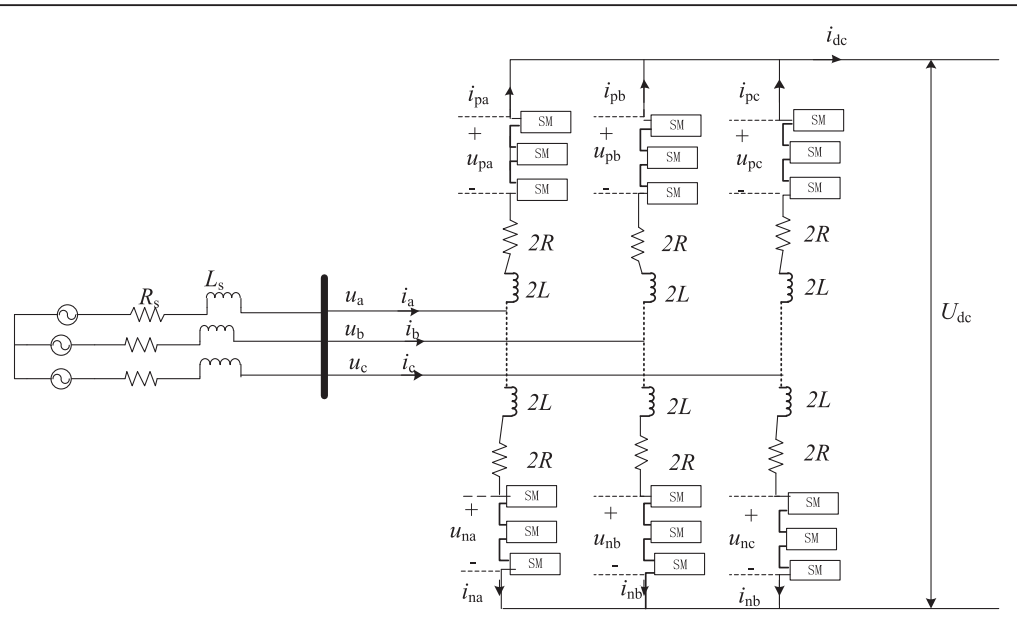

Fig. 1 Three phase MMC topology

$$
\left\{\begin{array}{l}
u_{a}-\left(u_{n a}-\frac{U_{d c}}{2}\right)=2 L \frac{d i_{n a}}{d t}+2 R i_{n a} \\
u_{b}-\left(u_{n b}-\frac{U_{d c}}{2}\right)=2 L \frac{d i_{n b}}{d t}+2 R i_{n b} \\
u_{c}-\left(u_{n c}-\frac{U_{d c}}{2}\right)=2 L \frac{d i_{n c}}{d t}+2 R i_{n c}
\end{array}\right.
$$

In the above equations, $2 \mathrm{~L}$ and $2 \mathrm{R}$ denote the equivalent arm inductance and resistance, respectively. Adding Eqs. (2) and (3) leads

$$
\left\{\begin{array}{l}
u_{a}-\left(u_{n a}-u_{p a}\right) / 2=L \frac{d i_{a}}{d t}+R i_{a} \\
u_{a}-\left(u_{n b}-u_{p b}\right) / 2=L \frac{d i_{b}}{d t}+R i_{b} \\
u_{c}-\left(u_{n c}-u_{p c}\right) / 2=L \frac{d i_{c}}{d t}+R i_{c}
\end{array}\right.
$$

According to Eq. (4), the time domain mathematic model of a $\mathrm{MMC}$ in abc coordinate is given by $[10,11]$.

$$
\left\{\begin{aligned}
\frac{d i_{a}(t)}{d t} & =-\frac{R}{L} i_{a}(t)+\frac{1}{L}\left[u_{a}(t)-\left(u_{n a}(t)-u_{p a}(t)\right) / 2\right] \\
\frac{d i_{b}(t)}{d t} & =-\frac{R}{L} i_{b}(t)+\frac{1}{L}\left[u_{b}(t)-\left(u_{n b}(t)-u_{p b}(t)\right) / 2\right] \\
\frac{d i_{c}(t)}{d t} & =-\frac{R}{L} i_{c}(t)+\frac{1}{L}\left[u_{c}(t)-\left(u_{n c}(t)-u_{p c}(t)\right) / 2\right]
\end{aligned}\right.
$$

Written Eq. (5) in phasor form yields

$$
\begin{aligned}
& \frac{d}{d t}\left[\begin{array}{c}
i_{a} \\
i_{b} \\
i_{c}
\end{array}\right]= {\left[\begin{array}{rrrr}
-\frac{R}{L} & 0 & 0 \\
0 & -\frac{R}{L} & 0 \\
0 & 0 & -\frac{R}{L}
\end{array}\right]\left[\begin{array}{c}
i_{a} \\
i_{b} \\
i_{c}
\end{array}\right] } \\
&+\left[\begin{array}{cccccc}
-\frac{1}{2 L} & \frac{1}{2 L} & 0 & 0 & 0 & 0 \\
0 & 0 & -\frac{1}{2 L} & \frac{1}{2 L} & 0 & 0 \\
0 & 0 & 0 & 0 & -\frac{1}{2 L} & \frac{1}{2 L}
\end{array}\right]\left[\begin{array}{l}
u_{n a} \\
u_{p a} \\
u_{n b} \\
u_{p b} \\
u_{n c} \\
u_{p c}
\end{array}\right] \\
&+\left[\begin{array}{ccc}
\frac{1}{L} & 0 & 0 \\
0 & \frac{1}{L} & 0 \\
0 & 0 & \frac{1}{L}
\end{array}\right]\left[\begin{array}{l}
u_{a} \\
u_{b} \\
u_{c}
\end{array}\right]
\end{aligned}
$$

Considering the uncertainty, external disturbances and system faults, the Eq. (6) can be written as follows

$$
\left\{\begin{aligned}
\dot{\mathbf{x}}(t) & =\mathbf{A x}(t)+\mathbf{B u}(t)+\mathbf{h}(t)+\Delta(t)+\mathbf{B}_{f} \mathbf{f}(t) \\
\mathbf{y}(t) & =\mathbf{C} \mathbf{x}(t)+\mathbf{D M}(t)
\end{aligned}\right.
$$

$$
\begin{gathered}
\text { where } \mathbf{x}(t)=\left[\begin{array}{c}
i_{a} \\
i_{b} \\
i_{c}
\end{array}\right], \mathbf{u}(t)=\left[\begin{array}{l}
u_{n a} \\
u_{p a} \\
u_{n b} \\
u_{p b} \\
u_{n c} \\
u_{p c}
\end{array}\right], \mathbf{A}=\left[\begin{array}{ccc}
-\frac{R}{L} & 0 & 0 \\
0 & -\frac{R}{L} & 0 \\
0 & 0 & -\frac{R}{L}
\end{array}\right], \\
\mathbf{B}=\left[\begin{array}{cccccc}
-\frac{1}{2 L} & \frac{1}{2 L} & 0 & 0 & 0 & 0 \\
0 & 0 & -\frac{1}{2 L} & \frac{1}{2 L} & 0 & 0 \\
0 & 0 & 0 & 0 & -\frac{1}{2 L} & \frac{1}{2 L}
\end{array}\right], \mathbf{h}(t)=\left[\begin{array}{ccc}
\frac{1}{L} & 0 & 0 \\
0 & \frac{1}{L} & 0 \\
0 & 0 & \frac{1}{L}
\end{array}\right]\left[\begin{array}{c}
u_{a} \\
u_{b} \\
u_{c}
\end{array}\right] .
\end{gathered}
$$

In Eq. (7), $\Delta(t)$ represents uncertainty and external disturbances generated during the actual modeling process. $\mathbf{f}(t)$ represents the system faults which are required to 
detect and identify. $\mathbf{M}(t)$ is measurement noise introduced by the measurement system. $\mathbf{B}_{f}, \mathbf{C}$ and $\mathbf{D}$ are known matrices with appropriate dimensions. $\mathbf{y}(t)$ is the system output. If $\boldsymbol{\Omega}(t)$ is used to represent $\boldsymbol{\Delta}(t)+\mathbf{h}(t)$, Eq. (7) can be written as follows.

$$
\left\{\begin{array}{c}
\dot{\mathbf{x}}(t)=\mathbf{A x}(t)+\mathbf{B u}(t)+\mathbf{\Omega}(t)+\mathbf{B}_{f} \mathbf{f}(t) \\
\mathbf{y}(t)=\mathbf{C} \mathbf{x}(t)+\mathbf{D M}(t)
\end{array}\right.
$$

For further analysis, the following assumptions are made:

1) Uncertainties in the system are norm-bounded, that is $\|\Delta(t)\| \leq V_{\Delta}$.

2) System matrix pair $(\mathbf{A}, \mathbf{C})$ is observable.

3) Uncertainties in the system meet the condition $\|\boldsymbol{\Omega}(t)\| \leq \gamma\|\mathbf{x}(t)\| \leq \mathbf{V}_{\Omega}$.

4) The $\mathbf{M}(t)$ in the system is norm-bounded, that is $\|\mathbf{M}(t)\| \leq V_{M}$.

5) The initial state of the system is zero.

\section{Design of full dimension state observer}

Fault diagnosis is carried out by full dimension state observer based on the state equation of flexible HVDC system [12-14]. It can be seen from Eq. (8) that $\boldsymbol{\Omega}(t)$ contains the system uncertainties and external disturbance, and the grid voltage $u_{a}, u_{b}, u_{c}$, which can be regarded as unknown nonlinear perturbation term.

A state observer is established according to Eq. (8):

$$
\{\dot{\hat{\mathbf{x}}}(t)=\mathbf{A} \hat{\mathbf{x}}(t)+\mathbf{B u}(t)+\mathbf{H}(\mathbf{y}(t)-\hat{\mathbf{y}}(t)) \hat{\mathbf{y}}(t)=\mathbf{C} \hat{\mathbf{x}}(t)
$$

In Eq. (9), $\mathrm{H}$ is a gain matrix to be designed. According to Eqs. (8) and (9), system residual state equation is given by:

$$
\left\{\begin{aligned}
\dot{\mathbf{x}}(t)-\dot{\hat{\mathbf{x}}}(t) & =(\mathbf{A}-\mathbf{H C})(\mathbf{x}(t)-\hat{\mathbf{x}}(t))+\mathbf{\Omega}(t)+\mathbf{B}_{f} \mathbf{f}(t) \\
& -\mathbf{H D M}(t) \mathbf{y}(t)-\hat{\mathbf{y}}(t)=\mathbf{C}(\mathbf{x}(t)-\hat{\mathbf{x}}(t))+\mathbf{D M}(t)
\end{aligned}\right.
$$

If $\mathbf{e}(t)=\mathbf{x}(t)-\hat{\mathbf{x}}(t)$ and $\mathbf{r}(t)=\mathbf{y}(t)-\hat{\mathbf{y}}(t)$, Eq. (10) can be written as follows:

$$
\left\{\begin{aligned}
\dot{\mathbf{e}}(t) & =(\mathbf{A}-\mathbf{H C}) \mathbf{e}(t)+\mathbf{\Omega}(t)+\mathbf{B}_{f} \mathbf{f}(t)-\mathbf{H D M}(t) \\
\mathbf{r}(t) & =\mathbf{C e}(t)+\mathbf{D M}(t)
\end{aligned}\right.
$$

In the design of the full dimension state observer, the impact of the fault and external disturbance or uncertainties on the residual should be considered. The transfer function from system uncertainties and external disturbance to residual $\mathbf{r}(t)$ is presented by $\mathbf{T}_{r d}$ whereas $\mathbf{T}_{r f}$ presents the transfer function from system fault to residual $\mathbf{r}(t)$. If the value of $\left\|\mathbf{T}_{r d}\right\|$ is small enough and the value of $\left\|\mathbf{T}_{r f}\right\|$ is big enough in the design, the designed observer will be robust. Therefore, the following performance index is used to design the fault diagnosis observer:

$$
J=\frac{\left\|\mathbf{T}_{r f}\right\|}{\left\|\mathbf{T}_{r d}\right\|}
$$

In practical applications, the above performance index can be equivalent to the following equation:

$$
\|r(t)\|_{\alpha} \leq \beta\|d(t)\|_{\alpha},\|r(t)\|_{-} \geq \eta\|f(t)\|_{-}
$$

Equation (13) can be solved by using multi-objective optimization methods and thus the robust control theory will be used to solve the performance optimization problem proposed by Eq. (13).

Theorem 1 The system represented by Eq. (8) satisfies the assumptions (1)-(5). Optimization index $\beta$ is given and satisfies the condition $\mathbf{D}^{T} \mathbf{D}-\beta^{2} \mathbf{I}<0$. In case of no fault in the system, if there are a positive definite symmetric matrix $\mathrm{R}$ and a constant factor $\varepsilon_{1}>0$ meeting the following linear matrix inequality:

$$
\left[\begin{array}{ccc}
\mathbf{R}(\mathbf{A}-\mathbf{H C})+(\mathbf{A}-\mathbf{H C})^{T} \mathbf{R}+\varepsilon_{1}^{-1} \mathbf{R}^{T} \mathbf{R}+\mathbf{C}^{T} \mathbf{C} & 0 & \mathbf{C}^{T} \mathbf{D}-\mathbf{R H D} \\
0 & \varepsilon_{1} \gamma^{2} \mathbf{I} & 0 \\
\mathbf{D}^{T} \mathbf{C}-(\mathbf{R H D})^{T} & 0 & \mathbf{D}^{T} \mathbf{D}-\beta^{2} \mathbf{I}
\end{array}\right]
$$

the residual system (11) is asymptotically stable and meets $\|r(t)\|_{\alpha} \leq \beta\|d(t)\|_{\alpha}$.

Theorem 2 The system represented by Eq. (8) satisfies the assumptions (1)-(5). Optimization index $\eta$ is given and satisfies the condition $\mathbf{D}^{T} \mathbf{D}-\eta^{2} \mathbf{I}<0$. In case of no fault in the system, if there are a positive definite symmetric matrix $\mathrm{T}$ and a constant factor $\eta_{1}>0$ meeting the following linear matrix inequality:

$$
\left[\begin{array}{ccc}
\mathbf{R}(\mathbf{A}-\mathbf{H C})+(\mathbf{A}-\mathbf{H C})^{T} \mathbf{R}+\eta_{1}^{-1} \mathbf{R}^{T} \mathbf{R}+\mathbf{C}^{T} \mathbf{C} & 0 & -\mathbf{C}^{T} \mathbf{D}+\mathbf{R H D} \\
0 & \eta_{1} \gamma^{2} \mathbf{I} & 0 \\
-\mathbf{D}^{T} \mathbf{C}+(\mathbf{R H D})^{T} & 0 & \eta^{2} \mathbf{I}-\mathbf{D}^{T} \mathbf{D}
\end{array}\right]
$$

The residual system (11) is asymptotically stable and meets $\|r(t)\|_{-} \geq \eta\|f(t)\|_{-}$.

Theorem 3 The system represented by Eq. (8) satisfies the assumptions (1)-(5). Optimization index $\beta>0, \eta>0$ are given. If there are positive definite symmetric matrix $\mathrm{R}, \mathrm{T}, \mathrm{H}$, constant factor $\varepsilon_{1}<0$ and $\eta_{1}>0$ meeting the following linear matrix inequality: 

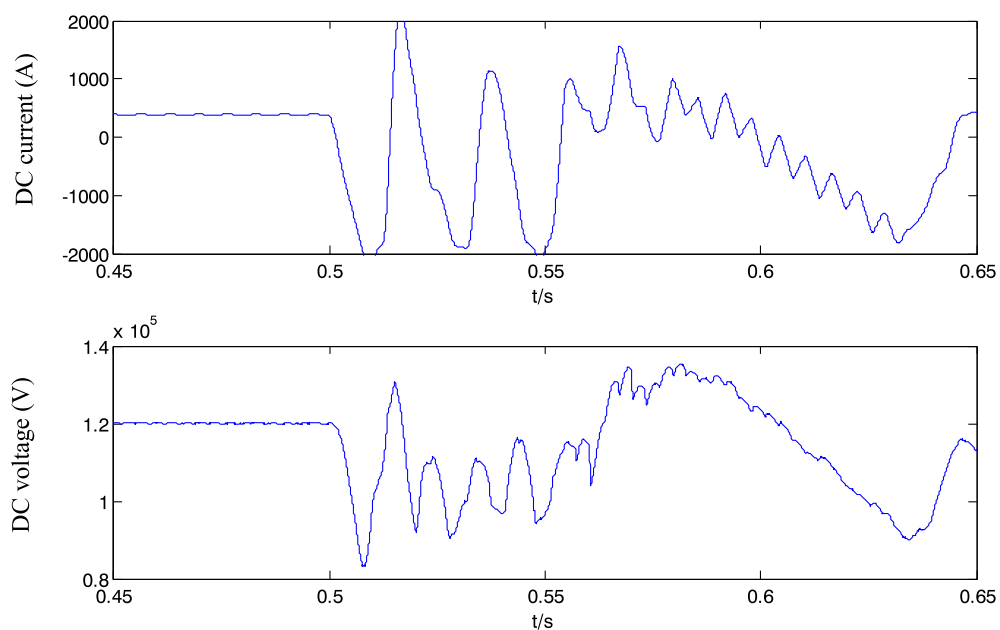

Fig. 2 Phase-A to ground fault

$$
\left[\begin{array}{ccc}
\mathbf{R}(\mathbf{A}-\mathbf{H C})+(\mathbf{A}-\mathbf{H C})^{T} \mathbf{R}+\varepsilon_{1}^{-1} \mathbf{R}^{T} \mathbf{R}+\mathbf{C}^{T} \mathbf{C} & 0 & \mathbf{C}^{T} \mathbf{D}-\mathbf{R H D} \\
0 & \varepsilon_{1} \gamma^{2} \mathbf{I} & 0 \\
\mathbf{D}^{T} \mathbf{C}-(\mathbf{R H D})^{T} & 0 & \mathbf{D}^{T} \mathbf{D}-\beta^{2} \mathbf{I}
\end{array}\right]
$$

$$
\left[\begin{array}{ccc}
\mathbf{R}(\mathbf{A}-\mathbf{H C})+(\mathbf{A}-\mathbf{H C})^{T} \mathbf{R}+\eta_{1}^{-1} \mathbf{R}^{T} \mathbf{R}+\mathbf{C}^{T} \mathbf{C} & 0 & -\mathbf{C}^{T} \mathbf{D}+\mathbf{R H D} \\
0 & \eta_{1} \gamma^{2} \mathbf{I} & 0 \\
-\mathbf{D}^{T} \mathbf{C}+(\mathbf{R H D})^{T} & 0 & \eta^{2} \mathbf{I}-\mathbf{D}^{T} \mathbf{D}
\end{array}\right]
$$

The residual system (11) is asymptotically stable and meets $\|r(t)\|_{\alpha} \leq \beta\|d(t)\|_{\alpha}$ and $\|r(t)\|_{-} \geq \eta\|f(t)\|_{-}$.

The gain matrix $\mathrm{H}$ of the full dimension state observer can be obtained from Theorem 3. The design process of gain matrix $\mathrm{H}$ takes into account the impact of system disturbances and uncertainties on the residual, and the sensitivity of the residual for faults.

\section{Determination of fault detection threshold}

When disturbances or uncertainties exist in the system, a fault detection threshold method is usually used to determine whether the system has a fault [15-17]. This section provides fault detection thresholds calculated according to the definition of norm.

Theorem 4 The system represented by Eq. (8) satisfies the assumptions (1)-(5). If the residual system (11) meets $\|\mathbf{r}(t)\|>\left(a \mathbf{V}_{\Omega}+b \mathbf{V}_{M}\right)\left(t-t_{0}\right)+c \mathbf{V}_{M}$, then system fault is detected,where $a=\sup _{t \in\left[t_{0}, t\right]}\|\mathbf{C \Psi}(t, s)\|, \quad b=\sup _{t \in\left[t_{0}, t\right]}$ $\|\mathbf{C \Psi}(t, s) \mathbf{H D}\|, c=\sup _{t \in\left[t_{0}, t\right]}\|\mathbf{D}\|$.

Proof According to the residual state Eq. (11) the following two equations can be derived:
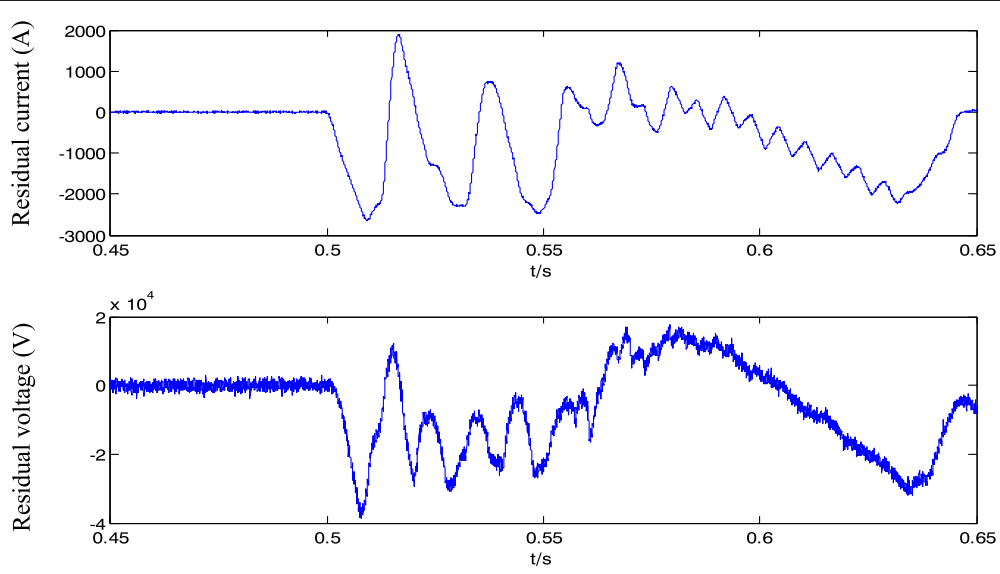

Fig. 3 Residual error curve during phase-A to ground fault 

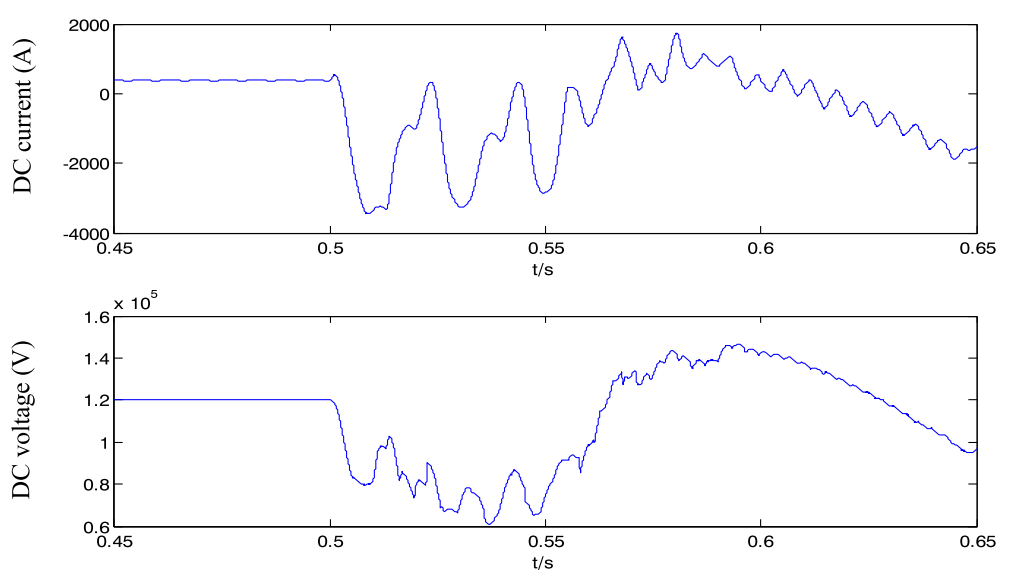

Fig. 4 Phase- $A B$ to ground fault

$$
\mathbf{e}(t)=\mathbf{\Psi}\left(t, t_{0}\right) \mathbf{e}\left(t_{0}\right)+\int_{t_{0}}^{t} \boldsymbol{\Psi}(t, s)\left[\mathbf{\Omega}(t)+\mathbf{B}_{f} \mathbf{f}(t)-\mathbf{H D M}(t)\right] d s
$$

$$
\begin{aligned}
\mathbf{r}(t)= & \mathbf{C}\left\{\boldsymbol{\Psi}\left(t, t_{0}\right) \mathbf{e}\left(t_{0}\right)+\int_{t_{0}}^{t} \boldsymbol{\Psi}(t, s)\left[\mathbf{\Omega}(t)+\mathbf{B}_{f} \mathbf{f}(t)-\mathbf{H D M}(t)\right] d s\right\} \\
& +\mathbf{D} \mathbf{M}(t)
\end{aligned}
$$

According to assumption (5), $\mathbf{e}\left(t_{0}\right)=0$. Thus

$$
\mathbf{r}(t)=\int_{t_{0}}^{t} \mathbf{C \Psi}(t, s)\left[\mathbf{\Omega}(t)+\mathbf{B}_{f} \mathbf{f}(t)-\mathbf{H D M}(t)\right] d s+\mathbf{D M}(t)
$$

Equation (21) can be obtained by seeking norm in both sides as

$$
\begin{aligned}
|\mathbf{r}(t)| \leq & \int_{t_{0}}^{t}\|\mathbf{C} \boldsymbol{\Psi}(t, s) \mathbf{\Omega}(t)\| d s+\int_{t_{0}}^{t}\left\|\mathbf{C} \boldsymbol{\Psi}(t, s) \mathbf{B}_{f} \mathbf{f}(t)\right\| d s \\
& +\int_{t_{0}}^{t}\|\mathbf{C} \boldsymbol{\Psi}(t, s) \mathbf{H D M}(t)\| d s+\|\mathbf{D} \mathbf{M}(t)\|
\end{aligned}
$$

where $a=\sup _{t \in\left[t_{0}, t\right]}\|\mathbf{C} \boldsymbol{\Psi}(t, s)\|, b=\sup _{t \in\left[t_{0}, t\right]}\|\mathbf{C} \boldsymbol{\Psi}(t, s) \mathbf{H D}\|, c=\sup _{t \in\left[t_{0}, t\right]}\|\mathbf{D}\|$

According to assumptions (1)-(4), Eq. (22) is obtained as

$$
\|\mathbf{r}(t)\| \leq \int_{t_{0}}^{t} a\|\mathbf{\Omega}(t)\| d s+\int_{t_{0}}^{t} b\|\mathbf{M}(t)\| d s+\|\mathbf{D} \mathbf{M}(t)\|
$$

Equation (22) can be simplified as
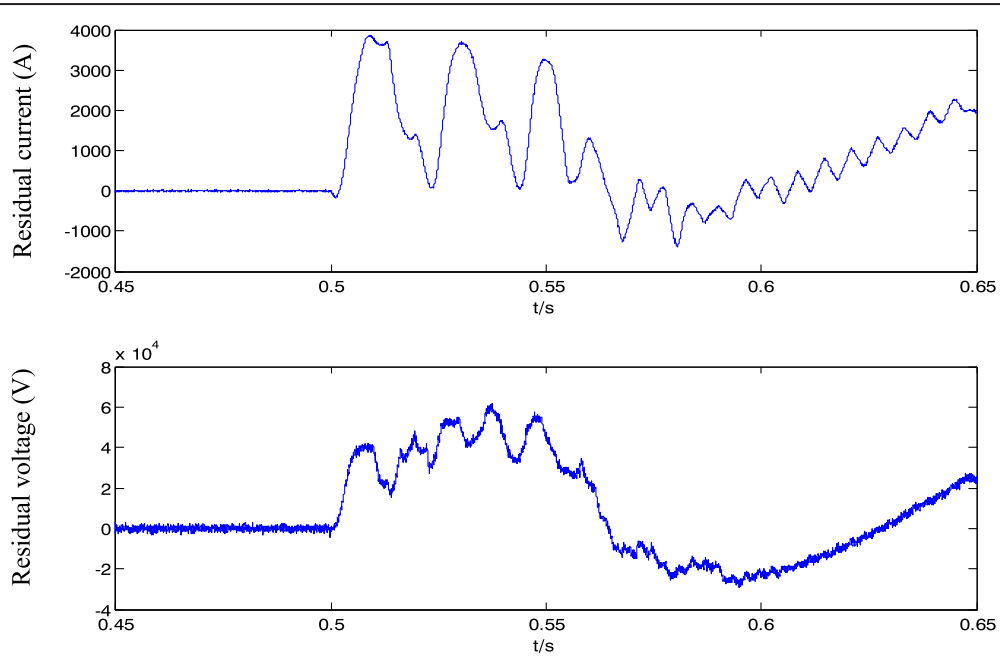

Fig. 5 Residual error curve during phase-AB to ground fault 

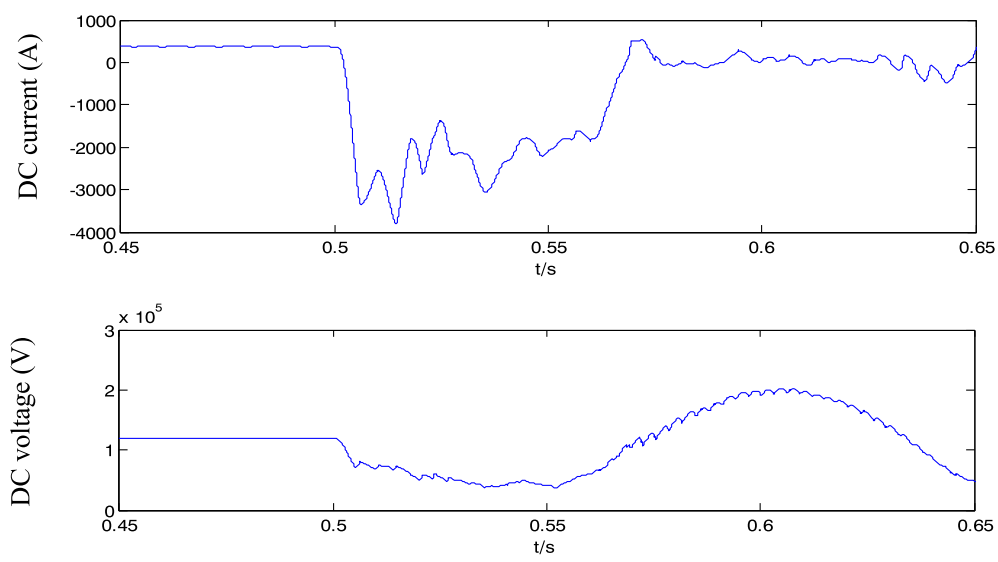

Fig. 6 Three phase to ground fault

$$
\begin{aligned}
\|\mathbf{r}(t)\| & \leq \int_{t_{0}}^{t} a \mathbf{V}_{\Omega} d s+\int_{t_{0}}^{t} b \mathbf{V}_{M} d s+c \mathbf{V}_{M} \\
& =a \mathbf{V}_{\Omega}\left(t-t_{0}\right)+b \mathbf{V}_{M}\left(t-t_{0}\right)+c \mathbf{V}_{M} \\
& =\left(a \mathbf{V}_{\Omega}+b \mathbf{V}_{M}\right)\left(t-t_{0}\right)+c \mathbf{V}_{M}
\end{aligned}
$$

Proof is done.

\section{Results}

\section{Simulation results}

According to the MMC-HVDC system state Eq. (7), common types of fault, e.g. phase A to ground fault, phase- $A B$ to ground fault, three phase to ground fault are simulated based on the 61-level MMC-HVDC system using Matlab/Simulink and RT-LAB.

The rated DC voltage of the system is $120 \mathrm{kV}$ and the rated active power is $50 \mathrm{MW}$. The rectifier controls active power control and the inverter controls the $\mathrm{DC}$ voltage. AC fault is simulated during 0.5 to $0.55 \mathrm{~s}$. The simulation output voltage and current waveforms are shown in Figs. 2, 3, 4, 5, 6 and 7.

\section{Phase-A to ground fault}

Figure 2 shows the DC bus voltage and current waveform when the phase-A to ground fault occurs in the rectifier side. The fault is introduced at $0.5 \mathrm{~s}$ when the system is running at steady state. The residual characteristics of the DC bus voltage and current can be calculated by the MMC-HVDC system residual state Eq. (13), as shown in Fig. 3. The baseline reference points of the HVDC fault observer output voltage and current are zero, which can be seen by comparing Figs. 2 and 3 . When the system operates normally, taking into account the existing uncertainties and various random disturbances, residual curve should fluctuate within a limited range. From Fig. 3 it can be seen that, after a system fault, the system output curves (the DC bus voltage and current) significantly deviate from zero and their normal
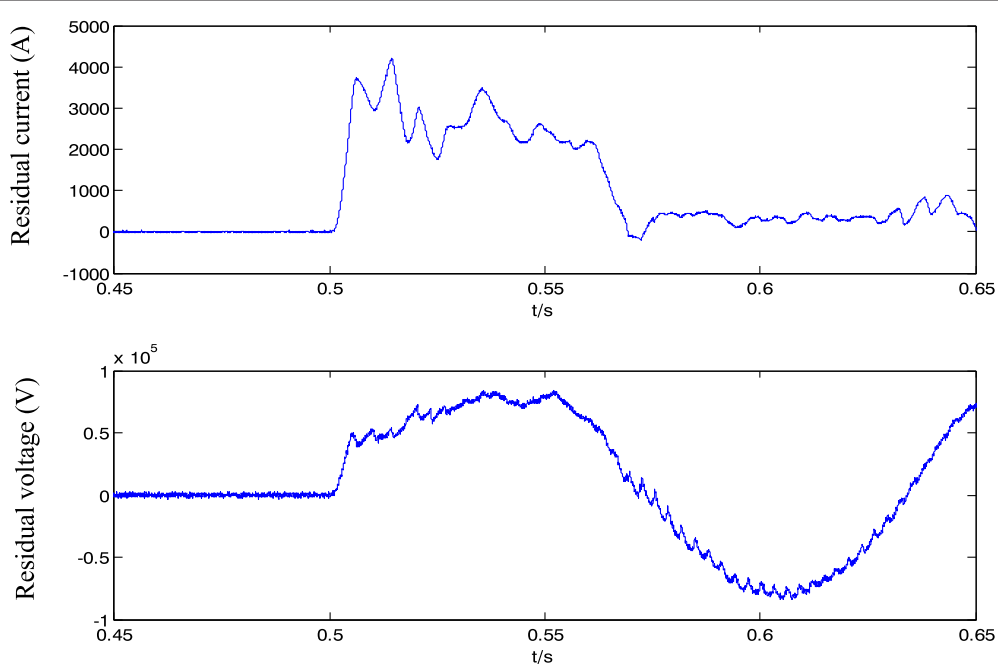

Fig. 7 Residual error curve during three phase to ground fault 
bands. The system's fault diagnostic threshold can be calculated according to Theorem 4 . If the residual waveform fluctuates within the calculated threshold, it is judged that the system is operating normally. If the residual waveform exceeds the calculated threshold, a fault is detected and immediate protection action should be taken. Furthermore, the fault identification and fault estimation can also be studied according to the residual waveform. As seen from the simulation, when $t>0.52 \mathrm{~s}$, it detects a fault in the system.

\section{Phase-AB to ground fault}

The waveforms during phase- $A B$ to ground fault are shown in Fig. 4 where the fault is introduced at $0.5 \mathrm{~s}$. Due to the existence of various disturbances and uncertainties in the system, measurement noise is inevitably introduced when measuring system output. The residual voltage and residual current waveforms are shown in Fig. 5. According to Theorem 4, the fault detection threshold is Jth $=0.136$ * 104. As seen from the simulation, when $t>0.52 \mathrm{~s}$, the fault is detected.

\section{Three phase to ground fault}

The waveforms during three phase to ground fault is shown in Fig. 6. The fault is again introduced at $0.5 \mathrm{~s}$. The residual voltage and residual current waveforms calculated according to residual system state equation are shown in Fig. 7. According to Theorem 4 , the fault detection threshold is Jth $=2.62 * 104$. As seen from the simulation, when $t>0.52 \mathrm{~s}$, the system fault is detected.

\section{Conclusions}

In this paper, a robust fault diagnosis method is proposed to detect system fault in MMC-HVDC power transmission systems. The advantage of the proposed method is that the state observer considers the system uncertainties and fault sensitivity. Therefore, the proposed method can quickly achieve system fault diagnosis and accurately complete fault identification. The simulation results have proved the effect of robust fault diagnosis.

\section{Authors' contributions}

ZQY analyzed and proposed the robust fault diagnosis method. QZ, PC and $\mathrm{QZ}$ completed the simulations on RT-LAB and the written of this paper. ALL the authors read and approved the final manuscript.

\section{Competing interests}

The authors declare that they have no competing interests.

\section{Author details}

${ }^{1}$ Xuchang KETOP Electrical Research Institute, Xuchang, China. ${ }^{2} X J$ Electric Co., Ltd, Xuchang, China.

Received: 13 May 2016 Accepted: 16 May 2016

Published online: 30 June 2016

\section{References}

1. Zhang, ST, \& Hao, JJ. (2012). Fault diagnosis based on multiple-models particle filter. Control Engineering of China, 19(5), 864-871.

2. Song, ZM, Guo, YH, Xun, TS, et al. (2012). Reaserch on HVDC transmission system fault analysis based on wavelet transform. Power System Protection and Control, 40(3), 100-104.

3. Bian, L, \& Bian, CY. (2014). Review on intelligence fault diagnosis in power networks. Power System Protection and Control, 42(3), 146-158.

4. Li, HW, Yang, DS, Sun, YL, et al. (2013). Study review and prospect of intelligent fault diagnosis technique. Computer Engineering and Design, 34(2), 632-637.

5. Wang, JL, Xia, L, Wu, ZG, et al. (2010). State of arts of fault diagnosis of power systems. Power System Protection and Control, 38(18), 210-216.

6. Dai, GF, Zhao, D, Lin, PF, et al. (2015). Study of control strategy for active power filter based on modular multilevel converter. Power System Protection and Control, 43(8), 74-80.

7. Gnanarathna, UN, Gole, AM, \& Jayasinghe, RP. (2011). Efficient modeling of modular multilevel HVDC converters (MMC) on electromagnetic transient simulation programs. IEEE Transactions on Power Delivery, 26(1), 316-324.

8. Peralta, J, Saad, H, Dennetiere, S, et al. (2012). Detailed and averaged models for a 401-level MMC-HVDC system. IEEE Transactions on Power Delivery, 27(3), 1501-1508.

9. Simon, P.T. Simplified dynamic model of a voltage sourced converter with modular multilevel converter design. IEEE/PES Power Systems Conference and Exposition. Seattle, USA, 2009: 1-6

10. Simon, P.T. Modeling the trans bay cable project as voltage-sourced converter with modular multilevel converter design. IEEE Power and Energy Society General Meeting. Michigan, USA, 2011: 1-8

11. Guan, M, \& Xu, Z. (2012). Modeling and control of modular multilevel converter based HVDC system under unbalanced grid conditions. IEEE Transactions on Power Electronics, 27(12), 4858-4867.

12. Zhu, QL, Peng, CH, Li, JF, et al. (2012). Fuzzy DTC of PMSM based on full order observer. Power Electronics, 46(1), 87-89.

13. Yang, JQ, \& Zhu, FL. (2014). Linear-matrix-inequality observer design of nonlinear systems with unknown input and measurement noise reconstruction. Control Theroy \& Applications, 31(4), 538-544.

14. Gao, H, \& Cai, XS. (2013). Functional obsever design for a class of nonlinear systems. Control Theory \& Applications, 30(9), 1207-1210.

15. Zhao, Y, Dong, S, \& Li, TY. (2010). A new adaptive threshold algorithm to partial discharge processing based on HHT-MDL criterion. Power System Protection and Control, 38(5), 45-50.

16. Zhu, XH, Li, YH, Li, N, et al. (2013). Novel observer-based on robust fault detection method for nonlinear uncertain systems. Control Theory \& Applications, 30(5), 644-648.

17. Qin, LG, He, X, \& Zhou, DH. (2015). A fault estimation method based on robust residual generators. Journal of Shanghai Jiaotong University, 49(6), 768-744.

\section{Submit your manuscript to a SpringerOpen ${ }^{\mathcal{O}}$ journal and benefit from:}

- Convenient online submission

- Rigorous peer review

- Immediate publication on acceptance

- Open access: articles freely available online

- High visibility within the field

- Retaining the copyright to your article

Submit your next manuscript at $>$ springeropen.com 